\title{
Un estudio hermenéutico de comparación textual de Job 38,36-37: a partir de la «música de cielos» de fray Luis de León*
}

\author{
Weixin $\mathrm{Bao}^{* *}$ \\ Universidad de Salamanca \\ ORCID ID: https://orcid.org/0000-0002-7064-0279
}

La música de las esferas es una de las concepciones importantes para entender varios escritos - tanto literarios como exegéticos- de fray Luis de León, como su Exposición del Libro de Job. Sin embargo, parece que esta idea tradicional del universo no ha dejado sus huellas en las traducciones bíblicas con las que estamos familiarizados hoy en día. Frente a tal perplejidad hermenéutica, concentrándose en Job 38,36-37, este trabajo pretende realizar un estudio de comparación textual y revisión exegética a partir de la exposición luisiana, a fin de conocer mejor los avatares de estos dos versículos enigmáticos con la ayuda de la «música de cielos».

Palabras Clave: Música de las esferas; Luis de León; Job; exégesis; la Biblia; cosmología.

A Hermeneutical Study of Textual Comparison of Job 38,36-37: From Fray Luis DE LEÓN's "MúsicA DE CIELOS".- The music of the spheres is one of the important conceptions to understand various works - both literary and exegetical - of fray Luis de León, such as his Exposición del Libro de Job. However, it seems that this traditional idea of the universe has not made its mark on the biblical translations with which we are familiar today. Faced with such hermeneutical perplexity, concentrating on Job 38,3637 , this work aims to carry out a study of textual comparison and exegetical revision based on the exposition of fray Luis, in order to better understand the vicissitudes of these two enigmatic verses with the help of the "música de cielos".

Keywords: Music of the Spheres; Luis de León; Job; Exegesis; The Bible; Cosmology.

* Este trabajo se ha llevado a cabo como proyecto financiado por China Scholarship Council (CSC), con el número matriculado 201806010344.

**id00769239@usal.es

Copyright: (C) 2021 CSIC. Este es un artículo de acceso abierto distribuido bajo los términos de la licencia de uso y distribución Creative Commons Reconocimiento 4.0 Internacional (CC BY 4.0). 


\section{INTRODUCCIÓN: OTRA CRUX INTERPRETUM DEL LIBRO DE JOB}

A lo largo de la historia de la traducción y exégesis bíblicas, en cuanto al Libro de Job, siempre hay numerosos debates sobre los detalles oscuros que nos quedan como nudos gordianos ${ }^{1}$. Los versículos 36-37 del capítulo XXXVIII se cuentan entre los que merecen el esfuerzo de ser investigados ${ }^{2}$. Esta vez, la curiosidad parte del comentario de fray Luis de León, un distinguido exégeta, teólogo y, más aún, un eximio humanista, prosista y poeta español del siglo XVI.

En su Exposición del Libro de Job, se observa que, al traducir y parafrasear este parágrafo, el poeta agustino repite muchas veces la expresión «música de cielos». Se trata de una de las concepciones importantes para entender varios escritos suyos, detrás de la cual se manifiesta su anhelo de la armonía, sobre la base de la idea cosmológica tradicional de la música de las esferas. Con tal interpretación luisiana, se nota que el entendimiento de San Jerónimo sobre estos dos versículos no solo se hereda con admiración, sino que también logra una vitalidad humanista con cierta coherencia.

Sin embargo, como lo ocurrido en otros ambiguos pasajes bíblicos, las traducciones de Job 38,36-37 varían mucho según las versiones. Además, una vez revisadas las más familiares para nosotros, nos daremos cuenta de que la interpretación jeronimiana o luisiana sobre la armonía universal ha perdido sus huellas. Es decir, hoy en día, queda casi sin ninguna resonancia, como una auténtica «música callada» ${ }^{3}$.

1 Acerca de los problemas hermenéuticos de Job, hay infinitos estudios tanto antiguos como modernos que no tendrían la necesidad ni posibilidad de exponerse aquí. Una prueba representativa puede verse en la serie majestuosa de Word Biblical Commentary: David J. A. Clines, Job 38-42 [WBC], vol. 18B (Nashville, TN: Nelson, 2011); y una reflexión nueva en español puede verse en Víctor Morla Asensio, Libro de Job: Recóndita armonía (Estella: Ed. Verbo Divino, 2017).

2 Sobre los estudios más específicos que se centran en Job 38,36-37, también contamos con ejemplos abundantes, entre los cuales destacan la bibliografía informativa de Clines (Job 38-42 [WBC], vol. 18B), especialmente págs. 1039-1046 y 1065 1067; Luis Alonso Schökel y José Luis Sicre Díaz, Job: comentario teológico y literario (Madrid: Ediciones Cristiandad, 2002) págs. 664-665, y Dominique BARTHÉLEMY, Critique textuelle de l'Ancien Testament, Tome V (Fribourg-Göttingen: Academic Press-Vandenhoeck \& Ruprecht, 2015) págs. 401-403; entre muchísimos otros.

3 Verso del poeta místico San Juan de la Cruz: Cántico espiritual, v. 68 en CA, o v. 73 en $\mathrm{CB}$. 
Así que cabe preguntar: ¿de dónde viene esa «música de cielos»? ¿Cómo y por qué se nos pierde de vista al final? ¿En qué contexto bíblico se encuadra y cómo vincula estos versículos de manera lógica? ¿Cómo los interpretan otros traductores y exégetas? ¿En qué consiste el o los rompecabezas para desentrañar el sentido de este párrafo oscuro? ¿Esta supuesta 'pérdida' es justificable o no? Frente a tal perplejidad hermenéutica, este presente trabajo intenta realizar un estudio de revisión exegética y comparación del texto de Job 38,36-37 en varias versiones de distintos idiomas, acudiendo tanto a las antiguas como a las modernas, a fin de acercarnos a los avatares de estos dos versículos enigmáticos con la ayuda de la «música de cielos».

\section{LA MÚSICA DE LAS ESFERAS: UNA CONCEPCIÓN COSMOLÓGICA CRISTIANIZADA}

\subsection{Una tradición cosmológica desde la Antigüedad hasta el Renacimiento}

«La gioia e la felicità suprema, per l'uomo, consiste nel conoscere gli arcani segreti del cielo, i misteriosi penetrali della natura, le menti divine, l'ordine dell'universo» ${ }^{4}$. No habría nada mejor que estas palabras del enciclopedista italiano Girolamo Cardano para exponer la actitud de los humanistas cristianos frente a la naturaleza y el universo, tal como fray Luis de León ante la «música de cielos», el punto de partida de nuestra investigación. De hecho, no se trata de una invención suya, sino de una de las tradiciones más antiguas de la concepción universal, que sonaba entre sus contemporáneos, dado que nos hallamos «no ante lugares comunes, sino ante los rudimentos del saber de la época» ${ }^{5}$.

La música de las esferas, denominada también como la armonía de las esferas o la música cósmica, es una concepción cosmológica del

${ }^{4}$ Eugenio Garin, L’Umanesimo italiano. Filosofia e vita civile nel Rinascimento (Roma-Bari: Laterza, 1986) pág. 231.

${ }_{5}$ Francisco Rico, El pequeño mundo del hombre: Varia fortuna de una idea en la cultura española (Barcelona: Ediciones Destino, 2005) pág. 145. 
tradicional modelo pitagórico-ptolemaico, según el cual la tierra está ubicada en el centro del cosmos y las esferas a su alrededor producen una armonía inaudible con sus movimientos incesantes ${ }^{6}$. Tal sistema astronómico, desarrollado por Pitágoras, Platón, Aristóteles hasta Ptolomeo, logró su popularidad gracias al Somnium Scipionis de Cicerón y el comentario de Macrobio ${ }^{7}$. Más tarde, con esfuerzos de los patrísticos, escolásticos y teólogos medievales y renacentistas, se configuró como una idea cristianizada, que llegó a emplearse en la exégesis bíblica ${ }^{8}$ y fue predominante hasta el siglo XVIII ${ }^{9}$.

La música y la cosmología van siempre juntas en el marco de esta concepción. Cualquier persona que esté familiarizada con las artes liberales lo estaría con esta vinculación íntima ${ }^{10}$. En otras palabras, cuando hablamos de la música, ya estamos tocando el universo. Para

${ }^{6}$ El número exacto de las esferas varía según los esquemas cosmológicos de épocas; cf. Isabel Rivers, Classical and Christian Ideas in English Renaissance Poetry (London-New York: Routledge, 2005) pág. 70.

7 Cf. Marco Tulio Cicerón, Sobre la república (Madrid: Gredos, 1984) pág. 166, y Ambrosius Theodosius Macrobius, Commentarii in Somnium Scipionis, II, iii (Leipzig: Teubner, 1963) págs. 103-107.

8 Cf. Leo Spitzer, «Classical and Christian Ideas of World Harmony: Prolegomena to an Interpretation of the Word 'Stimmung': Part I», Traditio 2 (1944) págs. 409-464, y Rivers, Classical and Christian Ideas, págs. 69-70. Además, aunque en el Talmud se muestran visiones cósmicas distintas de la pitagórico-ptolemaica, esta idea se fue aceptando en la tradición judía, especialmente después del siglo XII, cuando Maimonides empezó a describir el modelo universal como Ptolomeo e incluso lo aprovechó en su exégesis alegórica; cf. Jeremy Brown, New Heavens and a New Earth: The Jewish Reception of Copernican Thought (Oxford-New York: Oxford University Press, 2013) págs. 27-41.

${ }^{9}$ Una prueba puede verse en Andreas Cellarius, Harmonia macrocosmica, seu Atlas universalis et novus (Amsterdam, 1661). Además, hay que notar: aunque la teoría heliocéntrica generó un gran impacto en la cosmología tradicional, Copérnico conservó en su astronomía el sistema esencial aristotélico-ptolemaico; $c f$. Nicolás CoPÉRNICO, De revolutionibus orbium coelestium (Nürnberg, 1543), y Rivers, Classical and Christian Ideas, págs. 72-73.

10 Cf. David L. Wagner, The Seven Liberal Arts in the Middle Ages (Bloomington, IN: Indiana University Press, 1983) págs. 171-172; Simeon K. HenINGER, Touches of Sweet Harmony: Pythagorean Mythology and Renaissance Poetics (San Marino, CA: The Huntington Library, 1974) págs. 178-179, y Andrew James Hicks, Composing the world: harmony in the Medieval Platonic cosmos (New York: Oxford University Press, 2017) págs. 68-70. 
Boecio, quien clasificó la música en tres tipos, una división tan admirada y divulgada en el Renacimiento, la música instrumental es una imitación de la universal ${ }^{11}$. Además, desde Pitágoras, tanto la música como el cosmos tienen su cimiento en el número ${ }^{12}$, núcleo que reúne todas las disciplinas del quadrivium, con el cual se construyen proporciones e intervalos adecuados que conducen directamente a la belleza y la armonía ${ }^{13}$, o sea, al orden de la gran labor del Creador. Esta visión con la esencia armoniosa consiste en un principio estético sumamente relevante para los renacentistas, entre los cuales se destaca el ejemplo de fray Luis ${ }^{14}$.

\subsection{La «música de cielos» en fray Luis de León}

Aparte de una preferencia personal por el argumento, así como por el valor tanto teológico como literario, lo atractivo de Job para nuestro exégeta, quien conocía perfectamente su dificultad, no menos consiste en su dimensión exegética, cuya oscuridad supondría un reto para su oficio ${ }^{15}$. A través de las palabras que explican su objetivo y los pasos concretos en su Dedicatoria ${ }^{16}$, se perciben unos puntos fundamentales para entender su

${ }^{11}$ Cf. Boecio, Sobre el fundamento de la música (Madrid: Gredos, 2009) págs. 76-83.

12 Cf. Heninger, Touches of Sweet Harmony, págs. 91-93; SAn Agustín, Sobre la música (Madrid: Gredos, 2007), y Francisco DE Salinas, Siete libros sobre la música (Madrid: Alpuerto, 1983), entre otros.

13 Cf. Heninger, Touches of Sweet Harmony, págs. 93-100, y Garin, L'Umanesimo italiano, págs. 152-153. E incluso hasta Kepler todavía sostiene la idea de que la estructura del cosmos se asienta sobre la base de la proporción geométrica y musical, desarrollando la tradicional concepción de la armonía cósmica; $c f$. Johannes KePLER, Harmonices Mundi (Linz, 1619), y Rivers, Classical and Christian Ideas, pág. 73.

${ }^{14}$ Cf. David López García y Rosario Siminiani Ruiz, Y como esta compuesta de números concordes. Números y emblemas en la poesía de fray Luis de León (Murcia: Universidad de Murcia, 1997) págs. 11-12.

15 Cf. fray Luis de León, Exposición del Libro de Job, ed. Javier SAn José Lera, vol. I (Salamanca: Ediciones de la Universidad de Salamanca, 1992) págs. 45-47, y Judith RauchWARger, «Fray Luis de León's Exposición del Libro de Job», Recherches Augustiniennes 11 (1976) págs. 285-303.

${ }^{16}$ Fray Luis DE LeÓn, Exposición del Libro de Job, Obras completas castellanas, ed. P. Félix García, vol. II (Madrid: Biblioteca de Autores Cristianos, 1991) pág. 28. 
expositio, incluidos los términos pertinentes a la 'música': 1. la admiración y el respeto por parte del exégeta tanto al texto hebreo original como a la Vulgata ${ }^{17} ; 2$. el método exegético luisiano con énfasis en el sentido literal, que no solo se lleva a cabo a base de un fundamento filológico de dimensión humanista, sino también de sus preocupaciones teológicas y morales ${ }^{18}$; 3. la destacada característica poética de su traducción y paráfrasis, a fin de ser más atractivas para sus receptores, transmitiendo la sabiduría divina por medio del encanto literario ${ }^{19}$.

Nuestro autor nunca llama a sus estudios exegéticos ni comentario ni paráfrasis ni anotaciones, sino exposición en castellano y expositio o explanatio en latín, con la que expresa su deseo de abrir un camino nuevo entre los humanistas y los escolásticos del comentario, que venían

17 Aparte del motivo de una alabanza sincera, no se debe ignorar la tensión del ambiente histórico de la Contrarreforma en el que llevaron a cabo los estudios bíblicos fray Luis y sus contemporáneos. Después del Concilio de Trento, frente a la autoridad de la Vulgata, la traducción y la exégesis de los textos sagrados se encontraban al borde de un apuro peligroso, sobre todo para los hebraístas como él. Acerca de este peligro ideológico, véanse Javier SAN José LERA, «Libros y lectura en los procesos inquisitoriales de los profesores salmanticenses del siglo XVI», en Lectura y culpa en el siglo XVI, eds. María José Vega Ramos e Iveta NakLÁdalová (Barcelona: Universitat Autònoma de Barcelona, 2012) págs. 63-92, y Natalio Fernández Marcos y Emilia Fernández Tejero, Biblia y humanismo. Textos, talantes y controversias del siglo XVI español (Madrid: Fundación Universitaria Española, 1997).

${ }_{18}$ El sentido literal para fray Luis es una noción tan extensa que llega a abarcar todo lo que permita sugerirnos un texto bíblico, rompiendo los límites entre los sentidos exegéticos tradicionales. «El sentido literal es todo. La exégesis de fray Luis es literal en el sentido de literaria. Leer es desplegar, desarrollar, desenrollar todo el significado de la letra. [...] Para fray Luis el significante es significado si sabemos gozar la letra en toda su densidad»; apud Ciriaco Morón Arroyo, «Fray Luis de León: sistema y drama», en Fray Luis de León. Aproximaciones a su vida y su obra (Santander: Sociedad Menéndez Pelayo, 1989) págs. 311-335: 325. Para más estudios sobre el método de exposición y el sentido literal luisiano, véanse la Introducción de SAN José Lera en su edición citada, págs. 26-30, y Colin P. Thompson, La lucha de las lenguas: fray Luis de León y el Siglo de Oro en España (Salamanca: Junta de Castilla y León, 1995) págs. 96-102.

19 Sobre la importancia de la traducción como base de la exégesis literal, véanse la Introducción de SAN José Lera en su edición citada, págs. 35-41, y Sergio FernÁNDEZ LÓPEZ, «Del esfuerzo del traductor a la despreocupación del copista: la versión del Libro de Job de fray Luis de León», Hispanic review 78 (2010) págs. 345-367. 
disputando desde fines del siglo $\mathrm{XV}^{20}$. De hecho, no se trata de un rechazo, sino más bien de un eclecticismo de los métodos exegéticos, con el que encuentra su hermenéutica ideal: busca los mejores textos, compara manuscritos y ofrece interpretaciones lo más fieles posible, tomando el texto como totalidad en vez de versículos aislados y tratando de desplegar todas las posibles significaciones que admite, sin violar el significado de las palabras ${ }^{21}$.

A la vista de tales principios, vamos a ver, en el caso de Job 38,3637, cómo da su primer paso -es decir, una traducción literal-:

¿Quién puso en las entrañas del hombre sabiduría, o quién dió al gallo entendimiento?

¿Quién contará la orden de los cielos, y consonancia y música de cielos quién hará que duerma? ${ }^{22}$

Hay que tener en cuenta el pasaje correspondiente en la Vulgata:

Quis posuit in visceribus hominis sapientiam vel quis dedit gallo intellegentiam

Quis enarrabit caelorum rationem et concentum caeli quis dormire faciet $^{23}$

Obviamente, se nota una coincidencia casi literal entre la traducción de fray Luis y la de Jerónimo, tanto en el entendimiento del sentido como en la estructura sintáctica, excepto la amplificatio llamativa del «concentum caeli» como la «consonancia y música de cielos». Para los renacentistas, la idea no era desconocida ni extravagante, que quedaría más clara con las declaraciones del exégeta. En primer lugar, indica el papel que desempeñan estos versículos en

${ }^{20}$ Cf. Ciriaco Morón Arroyo, «Espesor de la letra. La hermenéutica de fray Luis de León», en Fray Luis de León: historia, humanismo y letras, eds. Víctor GARCíA DE la Concha y Javier SAn José Lera (Salamanca: Universidad de Salamanca, 1996) págs. 299-312: 308-309.

${ }^{21} C f$. Morón Arroyo, «Espesor de la letra», pág. 309.

22 Fray Luis DE LEÓN, Exposición, vol. II, pág. 817.

${ }^{23}$ Los textos de la Vulgata en este trabajo están tomados de la Biblia Políglota Complutense (1514-1517): Vetus Testamentum multiplici lingua nunc primo impressum. Et imprimis Pentateuchus hebraico greco atque chaldaico idiomate. Adjuncta unicuique sua latina interpretatione, 1514 , fol. $75 \mathrm{v}-76 \mathrm{r}$. 
el sentido retórico: entrelazar lo que procede con lo que le sigue, orientando la mirada de las cosas que aparecen en las alturas a las terrenales, incluido al hombre mismo ${ }^{24}$. Fray Luis defiende la traducción de Jerónimo sobre el gallo, sosteniendo que el santo lo entiende mejor que los que lo interpreten como el corazón. Luego da sus explicaciones concretas, que se podrían resumir de la manera siguiente: 1. Partiendo de las entrañas del hombre de 36a, el enfoque sigue yendo hacia abajo hasta el gallo de 36b, cuyo instinto es ignorado por el hombre; 2. Tanto en el hombre como en el gallo, existe algo paralelo: el cuerpo humano, que se encuentra en la tierra, cuenta con el alma, que conduce a lo divino, así como el animal: tan ordinario en el mundo pero tan particular por su sabiduría que viene del Creador, por lo cual se establece una antítesis implícita entre el cielo y la tierra; 3. En comparación con el corazón, la traducción del 'gallo' es más coherente con los dos versículos siguientes, que se desarrollan efectivamente en torno al instinto de este animal ${ }^{25}$.

Cuando interpreta la sabiduría del gallo, el exégeta la vincula estrechamente con el movimiento de los cielos $^{26}$, aludiendo a la armonía cósmica:

Que es decir que quién como el gallo contará la orden, esto es, los movimientos del cielo y sus puntos y horas, para puntualmente dar señal con la voz y quién como él atinará a la consonancia que entre sí los

${ }^{24} C f$. Luis de León, O. C. C., vol. II, pág. 634.

25 Cf. Luis de León, O. C. C., vol. II, pág. 634.

${ }^{26}$ Causarían confusiones al parecer las formas morfológicas del cielo en el comentario parafrástico luisiano, a veces en singular, otras veces en plural. Creo que, excepto los casos evidentes donde indica el cielo físico, el firmamento, o la morada divina donde reside Dios, al referirse a la música cósmica, la palabra «cielo» tanto en singular como en plural tiene un mismo sentido que el de «esfera». Es decir, en ciertos casos, supone un espacio en dimensión cosmológica. Tal ambigüedad tiene su explicación en Aristóteles, quien explica que se habla del cielo en tres sentidos: en primer lugar, «llamar cielo a la extremidad <del universo> y a lo más alto, donde decimos también que reside toda divinidad»; en segundo lugar, llamamos cielo «al cuerpo contiguo al orbe extremo del universo, donde $<$ se hallan $>$ la luna, el sol y algunos de los astros»; últimamente, «al cuerpo englobado por el orbe extremo: en efecto, solemos llamar cielo a la totalidad y al universo»; apud Aristóteles, Acerca del cielo. Meteorológicos, I, 9, 278b-279a (Madrid: Gredos, 1996) págs. 85-86. 
cielos tienen, moviéndose, o quién consuena y hace música con el cielo como él, acordando su cantar con sus altos y bajos ${ }^{27}$.

Si la interpretación luisiana sobre el versículo 36 muestra algo parecido al comentario de San Gregorio en sus Moralia, que gozaba de una extraordinaria difusión e influencia en el siglo XVI, fray Luis explica el 37 de una manera distinta: al traducir el verbo de $37 \mathrm{~b}$ por 'dormir', la «música de cielos» se identifica con la noche sosegada ${ }^{28}$. Una idea similar se encuentra en varios escritos suyos, entre los cuales se destaca la Oda VIII «Noche serena», que expresa sus reflexiones sobre las leyes del movimiento del universo en la contemplación del cielo estrellado, para la cual el citadísimo pasaje del capítulo «Príncipe de paz» de la obra maestra De los Nombres de Cristo del mismo autor puede considerarse una glosa acerca de cómo se produce esta armonía:

[...] el ejército de las estrellas, puesto como en ordenanza y como concertado por sus hileras, luce hermosísimo, y adonde cada una de ellas inviolablemente guarda su puesto, adonde no usurpa ninguna el lugar de su vecina, ni la turba en su oficio, ni menos, olvidada del suyo, rompe jamás la ley eterna y santa que le puso la Providencia $[\ldots]^{29}$

Evidentemente, fray Luis intenta dar una interpretación coherente sobre Job 38,36-38, centrándose en el instinto del gallo sobre el movimiento de los cielos. Es decir, no lo entiende en un sentido meteorológico sino astrológico, siguiendo el paso de Jerónimo, pero en una dimensión más parafrástica y literaria, conforme con su propósito de desvelar lo oculto del mensaje divino de una manera atractiva.

\section{Comparación textual de diversas versiones}

Sin embargo, nos resultaría sorprendente el revisar estos versículos en otras versiones, tanto antiguas como modernas. La 'música' que pone

27 Luis de LeÓn, O. C. C., vol. II, págs. 634-635.

28 «Y llama música de cielos a las noches puras [...] y en una cierta manera se oye su concierto y armonía admirable»; apud Luis DE León, O. C. C., vol. II, pág. 635.

${ }^{29}$ Fray Luis de León, De los nombres de Cristo, ed. Javier SAn José Lera (Barcelona: Galaxia Gutenberg-Círculo de Lectores, 2008) pág. 244. 
de relieve el erudito bíblico apenas se encuentra presente en otro lugar. Más aún, los interpretan con una disparidad enorme, que indudablemente afectará a la coherencia de todo el contexto semántico en el que se desarrollan. No hay que olvidar las relaciones tan estrechas entre el gallo del 36 y la armonía del 37, que se explican mutuamente en el comentario luisiano, razón por la cual en la investigación estos versículos no deben considerarse aislados sino como un conjunto.

\subsection{El hebreo original y las primeras versiones ${ }^{30}$}

Ante todo, para averiguar tal desconcierto a partir de la 'música', los pasos preliminares deberían consistir en remontarse al texto bíblico original y las primeras traducciones. No obstante, los problemas comienzan enseguida al colacionar la Vulgata y la Septuaginta con el hebreo ${ }^{31}$ :

Job 38,36:

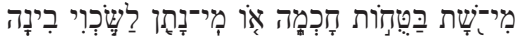

Quis posuit in visceribus hominis sapientiam vel quis dedit gallo intellegentiam

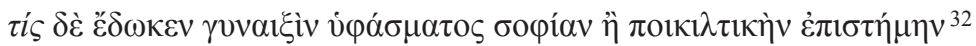
Job 38,37:

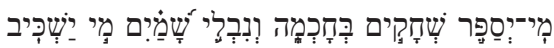

\footnotetext{
${ }^{30}$ Hay que declarar que, aunque querría e intentaría, lejos del objetivo del presente trabajo, realizar un completo análisis filológico sobre el texto original y todas las primeras versiones del AT, lo cual, lamentablemente, está fuera del alcance de la autora, ni hebraísta ni helenista. Serán bienvenidas las críticas por parte de los expertos interesados. Además, tengo que expresar mi agradecimiento al Sr. Lechao Tang del programa Bible and the Ancient Near Eastern Studies de la Hebrew University of Jerusalem, por sus ayudas generosas en este trabajo, sobre todo en aspectos filológicos de los textos en hebreo y arameo.

31 Si no se indica en particular, este trabajo cita el texto hebreo de Job de la edición BHS: Biblia Hebraica Stuttgartensia, eds. Karl Eldiger y Wilhem Rudolf (5 ${ }^{\text {a }}$ ed. Stuttgart: Deutsche Bibelgesellschaft, 1997) pág. 1269.

${ }^{32}$ El texto en griego se toma de la Editio altera de Alfred RAHLFs y Robert HANHART, Septuaginta: Id est Vetus Testamentum graece iuxta LXX interpretes, vol. II (Stuttgart: Deutsche Bibelgesellschaft, 2006) pág. 336.
} 
Quis enarrabit caelorum rationem et concentum caeli quis dormire faciet

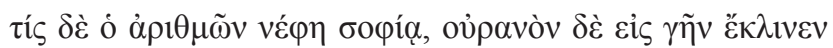

El versículo 36 en la Septuaginta nos desorienta por completo, no solo por su diferencia en comparación con la Vulgata, sino también por su incoherencia tanto con el versículo siguiente como con todo el contexto del capítulo. Si nos fijamos solamente en este versículo, sería fácil llegar a la conclusión de que los LXX utilizaron una Vorlage distinta de la de Jerónimo. Sin embargo, todavía no la conocemos con mucha se$\operatorname{guridad}^{33}$ y resultaría más justificable atribuir esta divergencia a un entendimiento distinto sobre algunas voces hebreas, bien por errores generados en la transmisión, bien por maneras desiguales de vocalización. Según Dhorme, los LXX marcharon por un camino equivocado, relacionando thwt con twh (hilar), de modo que parafrasearon el versículo de tal manera en vez de cuidar el verdadero sentido literal; en cambio, la Vulgata está más cerca del texto original ${ }^{34}$.

Si bien la versión griega ha ejercido influencia sobre las que la tienen como base, como la Vetus Latina ${ }^{35}$, parece que la Vulgata nos ha dado una traducción más convincente. En el versículo 36, traduce טִ̣in por 'visceribus', teniendo a la vista la presencia de la misma voz en Sal $51,8^{36}$, que se concibe como la 'parte interior', mientras que algunos rabinos lo entienden como 'riñones' -otra polémica de la que hablaremos después-, cuya raíz probablemente viene de que sig-

${ }^{33}$ No pocos estudiosos sostienen que los LXX desarrollaron sus trabajos sobre la base de un texto hebreo muy parecido al Texto Masorético; $c f$. Harry M. OrLinsky, «Studies in the Septuagint of The Book of Job», Hebrew Union College Annual 28 (1957) págs. 53-74; Homer Heater, A Septuagint Translation Technique in The Book of Job (Washington, DC: The Catholic Biblical Association of America, 1982) págs. 5-6, y Natalio Fernández Marcos, «The Septuagint Reading of the Book of Job», en Filología Bíblica y Humanismo (Madrid: Consejo Superior de Investigaciones Científicas, 2012) págs. 113-127: 115-116.

34 Édouard Paul Dhorme, Le Livre de Job (Paris: Gabalda, 1926) pág. 540.

35 Bibliorum sacrorum latinae versiones antiquae, seu Vetus italica: quae cum vulgata latina, \& cum textu graeco comparantur, Tomus primus, pars secunda (Parisiis, 1751) pág. 901.

36 Sal 50,8 en la Vulgata. 


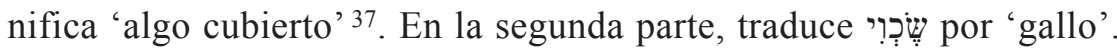
El problema reside en que se trata de un hápax legómenon en la Escritura y, más aún, ni su etimología ni su significado queda cierto. Pero generalmente, tanto los cristianos como los judíos se inclinan a interpretar esta palabra como 'gallo'.

Dejando a un lado el motivo filológico de esta traducción, lo más plausible sería su relación consecuente con la primera parte del versículo siguiente, interpretando ספספ": por 'enarrabit', que viene de ספר (enumerar, contar; recontar, narrar, relatar, describir) ${ }^{38}$ y ambos aspectos de cuyo doble sentido se emplean en el $\mathrm{AT}^{39}$. Evidentemente, aquí la Vulgata toma el significado derivado de la palabra, desviándose de la opción por el denotado de los LXX. Ambas traducciones del verbo tienen que ver con sus respectivos complementos directos: una simplemente toma vé $\uparrow \eta(n u-$ bes), mientras que la otra pone חְָָָָ en acusativo ('rationem'), ignorando la preposición ᄁ̦̣ (con, en) adjuntada a aquel sustantivo. Más aún, Jerónimo

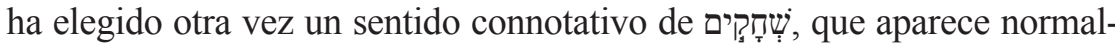
mente en esta forma plural, cuyo sentido original es 'polvo' por su raíz שחק (frotar, batir, pulverizar), que se extiende a 'nubes' e incluso a 'cielos' en términos generales ${ }^{40}$. En $37 \mathrm{~b}$ las dos versiones tampoco llegan a un consenso en lo referente a la polisemia de נֶרֶל (piel, cuero; pellejo, odre; arpa; etc. $)^{41}$, de la cual Jerónimo aprovecha el sentido más conforme a su traducción de la primera parte, parafraseando el instrumento en 'concentum', vinculado íntimamente con la armonía y la música, para aludir al constante y concorde movimiento de los cielos ${ }^{42}$.

37 Ernest KLeIN, A Comprehensive Etymological Dictionary of the Hebrew Language for Readers of English (Jerusalem: Carta, 1987) pág. 241, s. v. טָiฺn.

38 KleIn, A Comprehensive Etymological Dictionary, pág. 455, s. v. ספר.

39 Para el primer sentido ('contar, numerar'): Gen 15,5; Dt 16,9; Job 14,16; 31,4; Sal 40,5, etc.; para el segundo el segundo ('narrar, relatar'): Gen 24,66; 40,9; Ex 18,8; Job 28,27, Sal 19,1, etc.

40 KleIn, A Comprehensive Etymological Dictionary, pág. 651, s. v. שִָָׁ.

${ }^{41}$ KLeIn, A Comprehensive Etymological Dictionary, pág. 402, s. v. נֶֶ.

${ }^{42}$ Interpretación bien explicada por algunos comentaristas. $P$. ej., Scío parafrasea la traducción jeronimiana de una manera parecida a la luisiana; cf. La Biblia Vulgata Latina, traducida en español, y anotada conforme al sentido de los santos padres y expositores catholicos, por el P. Phelipe Scio de S. Miguel, de las Escuelas Pías, vol. VII del AT (Madrid, 1795) págs. 189 y 282. 
Así que no se puede ignorar en todo caso el lazo semántico entre este versículo y el precedente. Al contrario de la incoherencia existente en la Septuaginta, la Vulgata es plenamente consciente de las relaciones entre el animal y el movimiento cósmico, con lo cual la «música de cielos» en la exposición luisiana encuentra su base fundamental.

\subsection{Versiones medievales y renacentistas}

Desde la Baja Edad Media hasta el Renacimiento, aparecieron múltiples traducciones bíblicas. En España, la mayoría de ellas son versiones romanceadas ${ }^{43}$, aunque también hay raros ejemplos en latín. He aquí una comparación textual de Job 38,36-37 en unos testimonios medievales y renacentistas ${ }^{44}$, que se presentará en forma de tablas por el espacio limitado y para que el enfoque sea más visual y concebible, tomando en especial consideración algunos aspectos a los que atendemos:

\begin{tabular}{|l|l|l|}
\hline Texto subyacente & Traducción del latín & Traducción del hebreo \\
\hline Versiones bíblicas & E8, GE, Ayala & E3, Ferrara, E5, Arragel, Santillana, Oso \\
\hline
\end{tabular}

${ }^{43}$ No se niega en absoluto el valor de las traducciones al catalán o al romance navarro-aragonés, pero este trabajo se reduce a prestar atención a las versiones en castellano.

44 Todos los códices escurialenses se citan de Andrés Enrique-Arias y Fco. Javier Pueyo Mena, Corpus Biblia Medieval (BM) [en línea], siguiendo su norma de citar los manuscritos bíblicos antiguos. El acceso digital: <http://www.bibliamedieval.es> [última consulta: 22/07/2020]. Para más información sobre los códices y la traducción de la Biblia en la Edad Media, véase Margherita Morreale, «Bible translations», en Medieval Iberia: An Encyclopedia (London-New York: Routledge, 2003) págs. $168-173$. 


\begin{tabular}{|c|c|c|}
\hline Versículo & Conforme a la Vulgata & Discordante con la Vulgata \\
\hline $36 \mathrm{a}$ & $\begin{array}{l}\text { E8 (coraçones) }{ }^{45} \text {, } \\
\text { GE (entrañas) }{ }^{46}, \\
\text { Ayala (entrannas) })^{47}, \\
\text { Santillana (entrañas) }\end{array}$ & $\begin{array}{l}\text { E3 (riñones) })^{49}, \text { E5 } \text { (talentes) }^{50} \text {, } \\
\text { Arragel (reñones })^{51}, \text { Ferrara } \\
\text { (riñones) }^{52}, \text { Oso (riñones) }\end{array}$ \\
\hline
\end{tabular}

45 «¿Quí dio saber en los coraçones de los ombres, o quién dio al gallo entendimiento? ¿Quí contó la razón de los cielos, e la compaña del cielo, quí la fará dormir?»; apud $\mathrm{E} 8,218 \mathrm{va}$. Se trata de un romanceamiento prealfonsí a partir de la Vulgata; $c f$. Klaus Reinhardt y Horacio Santiago-Otero, Biblioteca bíblica ibérica medieval (Madrid: Editorial CSIC, 1986) pág. 26.

46 «Quien puso saber en las entrañas del omne, o quien dio entendimiento al gallo. Qui contara la razon de los cielos e fara dormir el canto del cielo», tomado del códice más antiguo de la Tercera Parte de la General Estoria (GE3), conocido como R (Biblioteca Pública de Évora ms. CXXV/2-3).

${ }^{47}$ «Qujen puso en las entrannas del omne el saber o qujen dio al gallo entendimjento. qujen contara la rrazon de los çielos \& el canto del çielo qujen dormjr fara», citado del códice Ms. 10138 de la Biblioteca Nacional de Madrid, incluido en BM bajo el epígrafe de Misc. XV, que con las Flores de los Morales de Job consiste en una traducción a partir del latín atribuida a Pedro López de Ayala.

48 «¿Quién puso en las entrañas sabiduría? ¿E quién dio al gallo entendimento? ¿Quién contará los firmamentos con saber? E los odres del cielo, ¿quién los faze yazer?»; apud Santillana, 164va. El texto de Job del manuscrito E4 está en coincidencia textual con el del códice MSS/10288 de la Biblioteca Nacional de España. Y ambos forman parte de la traducción que se suele denominar Biblia del Marqués de Santillana; $c f$. Klaus Reinhardt y Horacio Santiago-Otero, Biblioteca biblica ibérica medieval, pág. 23, y Andrés Enrique-Arias y Fco. Javier Pueyo Mena, «La Biblia completa del Marqués de Santillana», Revista de Filología Española 97:1 (2017) págs. 35-68.

49 «QQuién puso en los riñones saber, o quién dio al cuerpo entendimiento? ¿Quién enobleció los cielos con saber? e las nuves de los cielos, ¿quién las echó?»; apud E3, 435ra.

50 «QQuién puso en los talentes la sabiduría, o quién dio al gallo entendimiento? ¿Quién cuenta a los cielos con saber e a la redondeza de los firmamientos quién los faze sosegar?»; apud E5, 179rb.

51 «QQuién puso en los reñones del omne ciencia? ¿O quién dio al gallo entendimiento? ¿O quién renucia e cuenta los cielos con ciencia? ¿E las nubes de los cieblos quién faze dormir?», tomado de la Biblia de Arragel, 441va.

52 «QQuién puso en riñones sciencia, o quién dió al coraçón entendimiento? ¿Quién recontará cielos con sciencia, y nuves llenas de cielos quién fará descender?», citado de la edición facsimilar moderna, que reproduce el ejemplar R. 7957 de la Biblioteca Nacional de Madrid: La Biblia de Ferrara. Edición facsímil con introducción y notas edición facsimilar, eds. Iacob. M. HASSÁN y Uriel MACÍAS KAPÓN (Madrid: Sociedad Estatal Quinto Centenario, 1992) fol. 334v.

53 «¿Quién puso la sabiduría en los riñones, o quién dio al entendimiento la inteligencia? ¿Quién puso por cuenta los cielos con sabiduría? Y los odres de los cielos, 


\begin{tabular}{|c|c|c|}
\hline $36 b$ & $\begin{array}{l}\text { E8 (gallo), GE (gallo), Ayala (gallo), } \\
\text { E5 (gallo), Santillana (gallo), Arragel } \\
\text { (gallo) }\end{array}$ & $\begin{array}{l}\text { E3 (cuerpo), } \\
\text { Ferrara (coraçón), } \\
\text { Oso (entendimiento) } \\
\end{array}$ \\
\hline $37 \mathrm{a}$ & $\begin{array}{l}\text { E8 (contó la razón de los cielos), GE } \\
\text { (contara la razon de los cielos), Ayala } \\
\text { (contara la rrazon de los çielos), *E5 } \\
\text { (cuenta a los cielos con saber) }\end{array}$ & $\begin{array}{l}\text { E3 (enobleció los cielos con saber), } \\
\text { Arragel (renucia e cuenta los cielos } \\
\text { con ciencia), Santillana (contará } \\
\text { los firmamentos con saber), } \\
\text { Ferrara (recontará cielos con } \\
\text { sciencia), Oso (puso por cuenta los } \\
\text { cielos con sabiduría) }\end{array}$ \\
\hline $37 b$ & $\begin{array}{l}\text { E8 (la compaña del cielo; dormir), } \\
\text { GE (el canto del cielo; dormir), } \\
\text { Ayala (el canto del çielo; dormjr), } \\
\text { *E5 (la redondeza de los } \\
\text { firmamientos; sosegar) }\end{array}$ & $\begin{array}{l}\text { E3 (las nuves de los cielos; echó), } \\
\text { Arragel (las nubes de los cieblos; } \\
\text { dormir), Santillana (odres del } \\
\text { cielo; yazer), Ferrara (nuves llenas } \\
\text { de cielos; descender), Oso (los } \\
\text { odres de los cielos; parar) }\end{array}$ \\
\hline
\end{tabular}

Conjuntando la síntesis del cotejo, se nos delinearían unos puntos dignos de atención:

1. La mayor parte de las Biblias romanceadas en castellano no se tradujeron a partir del texto latino sino del hebreo ${ }^{55}$, una peculiaridad que se debe a la presencia de una gran comunidad de judíos en el territorio español hasta los finales del siglo XV.

2. En cuanto a la traducción de los versículos 36 y 37, existen variantes muy dispares en lo referente a los detalles al romancear los textos sagrados. Lo resultarían aún más patentemente si nos fijamos en

¿quién los hizo parar?», tomado de la llamada Biblia del Oso: La Biblia, que es, los Sacros Libros del viejo y nuevo Testamento. Trasladada en Español (Basilea, 1569) c1118.

54 Diversos códices como E5 eligen un verbo ambiguo en castellano: contar, que tiene sentidos tanto de numerar como de narrar. A la vista de la traducción de todo el versículo, creo que aquí probablemente expresa el significado segundo, aludiendo a las leyes del movimiento del universo en vez de la cantidad de las nubes. Así pues, aunque no es idéntica a la Vulgata, parece que esencialmente refleja una idea afín en el sentido cosmológico.

55 Afirmación apoyada por diversos estudiosos, véanse, entre otros, Sergio FernánDEZ LÓPEZ, «El Cantar de los Cantares de fray Luis de León: ¿Una traducción original?»,

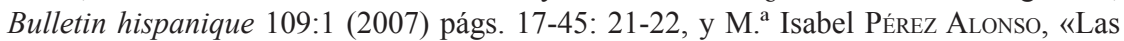
biblias romanceadas medievales o la aventura de traducir la 'verdad hebrayca' al castellano», Helmantica 62/188 (2011) págs. 391-415: 396-400. 
su respectiva Vorlage ${ }^{56}$. Parece que todas las versiones medievales y renacentistas a partir de la Vulgata mantienen una conformidad con ella, mientras que las de fuente hebrea adoptan una interpretación distinta. Lo mismo ocurre con la versión protestante de Casiodoro, manifestando la influencia por parte de la Biblia de Ferrara y la de Sanctes Pagnino.

3. Con respecto a las divergencias, aunque no faltan traducciones que abandonen el animal en 36b, más traductores -tanto sobre la base del hebreo como del latín- coinciden en relacionar este versículo con el gallo. Sin embargo, al entrar en el 37, escena de la 'música de cielos' de la que nos preocupamos desde el principio, nos daremos cuenta de que: los seguidores de la Vulgata mantienen fielmente el estilo jeronimiano, sobre todo en la resonancia de la armonía de las esferas y su lazo semántico con el gallo del versículo anterior; no obstante, por otra parte, los que parten de un texto hebreo prefieren aprovechar unos verbos ambiguos de raíz polisémica de 'contar', entre los cuales unos se inclinan al sentido 'numerar' y otros al 'narrar', sin referirse francamente al movimiento cósmico; más aún, en sus casos, en cuanto al 37b se decantan por la traducción por 'nubes' y 'odres', en vez de la vinculada con el orden y la armonía, mas tal entendimiento por el camino meteorológico perdería su coherencia con todo el contexto de estos versículos, que explicaré concretamente en el apartado hermenéutico.

Aparte de las versiones en romance de que hemos tratado, varios humanistas cristianos también hicieron sus esfuerzos para traducir la Biblia de las lenguas originales al latín con un cuidado filológico riguroso, entre los cuales se destacan los trabajos magníficos de Sanctes Pagnino, Robert Estienne, Benito Arias Montano, etc. He aquí una ojeada comparativa de las traducciones de Job 38,36-37:

Quis posuit in renibus sapientiam, aut quis dedit cordi intelligentiam?

Quis numerabit caelos sapientia, nubes plenas aqua descendere faciet? (Biblia de Pagnino, 1528) ${ }^{57}$

56 Por supuesto, no es el único factor que afecte al proceso de la traducción, pero este estudio se limita a tocar este más vinculado con el enfoque y objetivo del trabajo.

57 Sanctes Pagnino, Biblia. Habes in hoc libro prudens lector vtriusque instrumenti nouam translationem aeditam à reuerendo sacrae theologiae doctore Sancte Pagnino lucensi [...] (Lyon, 1528) fol. 184v. 
Quis indidit renibus sapientiam? aut quis indidit cordi intelligentiam?

Quis sapientia sua aetheri dictabit quae faciat? Et lagenas caeli quis sistet? (Biblia de Vatablo, 1584) ${ }^{58}$

Quis posuit in renibus sapientiam, aut quis dedit contemplationi intelligentiam?

Quis numerabit aethera in sapientia, et defluxus caelorum quis quiescere faciet? (Biblia Regia, 1568-1572) ${ }^{59}$

Colacionando estas traducciones, se nota que ninguna de estas tres Biblias, que parten del texto hebreo, está de acuerdo con la Vulgata, ni en el versículo 36 ni en el 37. En 36a, todas coinciden en traducir טִּחוֹ por renibus; en $36 \mathrm{~b}$, abandonan el gallo por completo, entendiéndolo bien por cordi bien por contemplationi ${ }^{60}$. En consecuencia, la armonía del movimiento cósmico se aleja, porque tanto Pagnino como Montano vierten $37 \mathrm{a}$ en numerar los cielos, aunque Leo Juda pone en énfasis el poder de control del Creador, en vez de aludir a una cantidad concreta. Por último, nos enfrentamos con dos opiniones totalmente contrarias sobre la interpretación de 37b: una supone 'hacer llover' y la otra es

58 Aquí nos limitamos a tomar en consideración la columna de la interpretatio nova de la Biblia de Vatablo de 1584, dado que la otra de esta edición cum duplici translatione es la Vulgata. Sin embargo, resultaría llamativo el cotejo entre la primera edición publicada por Robertus Stephanus en París en 1545 y la de 1584 en Salamanca, puesto que la traducción de Job 38,36-37 en la edición salmantina no es otra que la misma en la versión protestante de Zurich - es decir, la traducción del reformista suizo Leo Juda-, que se incluye en la primera edición parisiense, aunque el impresor cambió la versión nova por la traducción de Sanctes Pagnino en la segunda, que sacó a luz en 1557 en Génova. Las ediciones citadas: Biblia quid in hac editione praestitum sit, vide in ea quam operi praeposuimus, ad lectorem epistola (Lutetiae, 1545) fol. 20, y Biblia sacra cum duplici translatione, \& scholijs Francisci Vatabili [...], vol. I (Salmanticae, 1584) fol. 364r.

59 Tomado de la traducción de Arias Montano - o sea, de su corrección del texto de Pagnino- que se incluye en el Apparatus de la Biblia Regia: Sacrorum Bibliorum, Hebraicorum bibliorum Veteris Testamenti Latina interpretatio, opera olim Xantis Pagnini Lucensis: nunc verò Benedicti Ariae Montani Hispalensis [...] (Amberes, 1571) pág. 43. En cuanto al estudio más detallado al respecto, véase Natalio FERnÁNDEz MArCos y Emilia Fernández Tejero, «Pagnino, Servet y Arias Montano. Avatares de una Traducción Latina de la Biblia Hebrea», Sefarad 63:2 (2003) págs. 283-329.

60 En realidad, esta variante de contemplationi ya apareció en las notas marginales de la edición de Servet (1542): Biblia sacra ex Santis Pagnini tralatione, sed ad Hebraicae linguae amussim nouissime ita recognita, \& scholiis illustrata, ut plane noua editio uideri possit [...] (Lugduni, 1542) fol. 116r. 
'hacer parar la lluvia' 61 , pero lo común reside en que ambas están lejos del concierto jeronimiano.

Además, en el siglo XVI también hay no pocos comentarios específicos sobre Job de autores españoles, algunos de los cuales podrían servir de apoyo referencial para fray Luis de León ${ }^{62}$. En comparación con la expositio luisiana acerca de Job 38,36-37, la paráfrasis de Francisco Titelmann presenta grandes semejanzas en el entendimiento ${ }^{63}$ y la de Juan de Pineda también muestra una gran influencia de la Vulgata - sin perder de vista varias interpretaciones distintas- ${ }^{64}$, mientras que fray Diego de Zúñiga, con el que fray Luis comparte bastantes similitudes en muchos otros aspectos ${ }^{65}$, aquí sostiene una opinión totalmente diferente, entendiendo el concentum como un ruido meteorológico en vez de la música pitagórica ${ }^{66}$. La interpretación luisiana, al contrario, se realiza con una marcada concordia a la Vulgata. Así pues, a pesar de su conocida admiración por los trabajos de Pagnino y Vatablo ${ }^{67}$, por la que incluso sufrió ataques por parte de sus enemigos ${ }^{68}$, en este caso de Job 38,36-37 resultarían obvias

${ }^{61}$ La controversia sobre el significado del verbo tiene mucho que ver con el entendimiento sobre el versículo 38 pero poco con el objetivo de este trabajo, por lo cual no la desarrollaré.

${ }^{62} C f$. Víctor García dE la Concha, «'El honor de la lengua castellana': fray Luis de León, escritor», en El Siglo de Frai Luis de León (Salamanca: Universidad de Salamanca, 1991) págs. 149-167: 166.

${ }^{63}$ Francisco Titelman, Elucidatio paraphrastica in librum D. Job (Amberes, 1547) fol. $251 \mathrm{v}$.

${ }^{64}$ Ioannis DE PINEdA, Commentariorum in Job Lib, vol. II (Venetiis, 1619) págs. 576-587.

65 Cf. Javier San José Lera, «Fray Diego de Zuñiga y fray Luis de León, frente al Libro de Job», Ciudad de Dios 204:2-3 (1991) págs. 967-983.

66 Diego DE ZúÑIGA, Didaci a Stunica Salmanticensis Eremitae Augustiniani in Iob commentaria [...] (Toleti, 1584) págs. 814-815.

${ }^{67}$ Cf. Colin P. Thompson, La lucha de las lenguas, págs. 50-57, y Margherita Morreale, Homenaje a Fray Luis de León (Salamanca: Universidad de Salamanca, 2007) pág. 1007.

${ }^{68} C f$. José Luis González Novalín, «Inquisición y censura de Biblias en el Siglo de Oro. La Biblia de Vatablo y el proceso de fray Luis de León», en Fray Luis de León. Historia, humanismo y letras (Salamanca: Universidad de Salamanca, 1996) págs. 125-144. 
su inclinación hacia la Vulgata y su intención de aclarar la coherencia existente en ella, especialmente al tener en cuenta el pasaje paralelo en las versiones traducidas del latín.

\subsection{Versiones más modernas}

Si echamos un vistazo a las versiones modernas, nos dará la impresión de que se han desarrollado sobre la base de las antecedentes, pero nos sorprenderán con sus variantes y la pérdida casi por completo de la «música de cielos». Enfocando Job 38,36-37 en diversas versiones de distintos idiomas, la variedad se percibirá más claramente si presentamos la combinatoria de unos puntos controvertidos en forma de tabla:

\begin{tabular}{|l|l|l|l|}
\hline Versículo & $1^{\mathrm{a}}$ parte & $2^{\mathrm{a}}$ parte & Versiones \\
\hline \multirow{3}{*}{36} & $\begin{array}{l}\text { entrañas } / \\
\text { corazón }\end{array}$ & gallo & $\begin{array}{l}\text { Biblia de Scío }(1793)^{69}, \text { Biblia } \\
\text { Torres Amat }(1825)^{70}\end{array}$ \\
\cline { 2 - 4 } & interior / seno & $\begin{array}{l}\text { entendimiento / } \\
\text { corazón }\end{array}$ & $\begin{array}{l}\text { ERV }(1885)^{71}, \text { NIV }(1978)^{72}, \text { CUV } \\
(1919)^{73}\end{array}$ \\
\cline { 2 - 4 } & riñones & gallo & Delitzsch $(1866)^{74}$ \\
\hline
\end{tabular}

69 Véase la edición de Scío antes citada, págs. 188-189.

70 La Sagrada Biblia traducida de la Vulgata latina al español. Aclarando el sentido de algunos lugares con la luz que dan los textos originales hebreo y griego, e ilustrada con varias notas sacadas de los santos padres y expositores sagrados por D. Félix Torres Amat, Tomo II (Barcelona, 1884) pág. 384.

71 The interlinear Bible: the Authorised version and the Revised version; together with the marginal notes of both versions and central references (London: Cambridge University Press, 1907) pág. 703.

72 The Holy Bible: New International Version (Grand Rapids, MI: Zondervan, 2001) pág. 296.

73 Chinese Union Version, texto consultado en una edición relativamente reciente: The Holy Bible [en chino] (Shanghai: China Christian Council, 2009) pág. 508.

74 Franz Delitzsch, Biblical commentary on the Book of Job, vol. II (Edinburgh: T \& T Clark, 1866) pág. 325. 


\begin{tabular}{|c|c|c|c|}
\hline & ibis & gallo & $\begin{array}{l}\text { Bover-Cantera }(1947)^{75} \text {, Compañía } \\
\text { de Jesús }(1967)^{76} \text {, Schökel } \\
(1971)^{77} \text {, Nova Vulgata }(1979)^{78} \text {, } \\
\text { Dhorme }(1926)^{79} \text {, Bible de } \\
\text { Jérusalem }(1955)^{80} \text {, Gordis } \\
(1965)^{81} \text {, Scheindlin }(1998)^{72} \text {, } \\
\text { SBV }(1968)^{83} \text {, RCUV }(2010)^{84}\end{array}$ \\
\hline & Thoth & Sekwi & Pope $(1965)^{85}$ \\
\hline \multirow[t]{4}{*}{37} & $\begin{array}{l}\text { contar el orden / } \\
\text { explicar la disposición } \\
\text { de los cielos }\end{array}$ & $\begin{array}{l}\text { la armonía del cielo } \\
\text { / sus armoniosos } \\
\text { movimientos }\end{array}$ & Scío, Amat \\
\hline & contar las nubes & $\begin{array}{l}\text { odres / cántaros del } \\
\text { cielo }\end{array}$ & $\begin{array}{l}\text { Bover-Cantera, Compañía de Jesús, } \\
\text { Schökel, Nova Vulgata, Dhorme, } \\
\text { Jérusalem, ERV, NIV, Pope, } \\
\text { Scheindlin, CUV, SBV, RCUV }\end{array}$ \\
\hline & $\begin{array}{l}\text { contar los estratos de } \\
\text { las nubes }\end{array}$ & odres del cielo & Delitzsch \\
\hline & extender las nubes & cántaros del cielo & Gordis \\
\hline
\end{tabular}

75 Sagrada Biblia: version critica sobre los textos Hebreo y Griego, eds. José María Bover y Francisco Cantera Burgos, vol. I (Madrid: BAC, 1947) pág. 870.

${ }^{76}$ La Sagrada Escritura. Textos y comentario: Antiguo Testamento, eds. Profesores de la Compañía de Jesús, vol. III (Madrid: BAC, 2015) págs. 717-718.

77 Luis Alonso SchöKel, Job, en Los Libros Sagrados, vol. VIII (Madrid: Ediciones Cristiandad, 1971) pág. 187.

${ }^{78}$ Nova Vulgata Bibliorum Sacrorum editio, accesible en línea: $<$ http://www.vatican.va/archive/ bible/nova_vulgata/documents/nova-vulgata_vt_iob_tt.html\#38> [última consulta: 05/07/2020].

79 Dhorme, Le Livre de Job, págs. 540-542.

${ }^{80}$ La Sainte Bible, traduite en français sous la direction de l'École Biblique de Jérusalem (Paris: Éditions du Cerf, 1955) pág. 643.

${ }^{81}$ Robert GoRDIS, The book of God and man: a study of Job (Chicago-London: The University of Chicago Press, 1965) pág. 299. Se trata de una versión rabínica muy consciente de los últimos adelantos en el estudio bíblico.

82 Raymond P. Scheindurn, The Book of Job (New York-London: W. W. Norton \& Company, 1998) pág. 145.

83 Studium Biblicum Version, conocida popularmente como la versión Sigao. Citado de una edición reciente: The Holy Bible [en chino] (Hong Kong: The Studium Biblicum O.F.M., 2009) pág. 832.

84 The Holy Bible - Revised Chinese Union Version [en chino] (Hong Kong: The Hong Kong Bible Society, 2010) págs. 748-749.

${ }^{85}$ Marvin H. Pope, The Anchor Bible: Job (New York: Doubleday \& Company, 1974) pág. 290. 
Se observa que, desde las primeras versiones hasta hoy en día, efectivamente han variado mucho las opiniones de los traductores y comentaristas acerca de estos dos versículos, que se podrían resumir de la manera siguiente:

1. Excepto las versiones traducidas sobre la base de la Vulgata, ya no se puede encontrar ninguna que cuente con una interpretación idéntica a la jeronimiana.

2. No obstante, en la gran mayoría de las traducciones modernas en diversas lenguas, el gallo de $36 \mathrm{~b}$ todavía vive y prospera con vigor. Mientras tanto, cada vez más biblistas se vienen inclinando a entender טִּ como otra ave con sabiduría: el ibis, en vez de 'interior' o 'riñones' que aparecía con más frecuencia en las versiones medievales y renacentistas. Así que ahora este paralelismo ibis-gallo se ha convertido en la traducción más prevaleciente.

3. En cambio, en el versículo 37, ya casi no se puede encontrar ningún rastro de la tradición jeronimiana. A pesar de la fuerte presencia del gallo, la interpretación moderna se va alejando de la armonía universal. La mayoría de las versiones prefieren traducir שְִִׁ por por 'nubes' en vez de 'cielos' y entender numéricamente la cantidad. Más aún, aunque hay divergencias sobre el verbo de $37 \mathrm{~b}$, no existen batallas exegéticas alrededor de נֶֶֶ, sino un amplio consenso de otorgarle el significado de 'odre', y prácticamente nadie sigue el camino latino de vincularlo con lo músico, menos en el sentido cosmológico.

\section{ESTUDIOS HERMENÉUTICOS SOBRE LAS TRADUCCIONES POLÉMICAS}

A la vista de tal variedad de Job 38,36-37, es preciso aproximarnos a las fuentes y los avatares de una controversia tan discutida a lo largo de la historia, acudiendo a los estudios exegéticos realizados desde la Antigüedad hasta nuestros días e intentando juzgar el 'enmudecimiento' de la 'música' jeronimiana o luisiana. 


\section{1. ¿GALLO O CORAZÓN?}

La polémica acerca de la segunda parte del versículo 36 siempre se centra en la interpretación de la voz שְִֶׁ Como hemos visto, hay dos maneras distintas que predominan: una es relacionarla con la parte interior, el corazón, el alma, el espíritu, el entendimiento, o algo similar, pero esta opinión no sería convincente una vez tomada en consideración el contexto del discurso ${ }^{86}$; la otra, que resultaría más coherente y en consecuencia más aceptada, es entenderla como 'gallo'.

Esta interpretación, sin duda alguna, tiene mucho que ver con la tradición jeronimiana. Sin embargo, si damos un paso más, preguntando por qué Jerónimo la tradujo de esta manera, una gran cantidad de biblistas coincidirán en aconsejarnos recurrir a los comentarios rabínicos ${ }^{87}$.

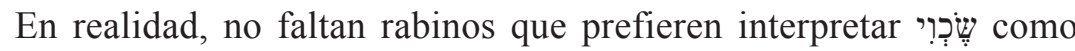
un apelativo del corazón, tales como Ibn Ezra y Rashbam ${ }^{88}$. Pero el Targum nos ofrece dos traducciones: 'corazón' y 'gallo', y la segunda también ha conseguido apoyo por parte de no pocos rabíes ${ }^{89}$. En cuanto a la procedencia precisa de esta interpretación, el exégeta muy influyente Rashi, a quien no pocos hebraístas cristianos del siglo XVI acudieron como una de sus fuentes de importancia, señaló la figura del

${ }^{86}$ Idea compartida por cada vez más estudiosos; $c f$. Rabbi Dr. Victor E. REICHERT, Job: Hebrew text \& English translation with an introduction and commentary (London-Jerusalem-New York: The Soncino Press, 1946) pág. 202; Robert Gordis, The Book of Job: Commentary, New Translation, and Special Studies (New York: Jewish Theological Seminary of America, 1978) págs. 452-453, y Naphtali Herz TuR-SinAI, The Book of Job: a new commentary (Jerusalem: Kiryath Sepher, 1957) págs. 533-534, entre otros.

87 Cf. Dhorme, Le Livre de Job, pág. 540; Profesores de la Compañía de Jesús, La Sagrada Escritura, pág. 717; Scheinduin, The Book of Job, págs. 218-219, y Delitzsch, Biblical commentary, pág. 326, entre otros.

${ }^{88}$ Cf. Mariano Gómez Aranda, El Comentario de Abraham ibn Ezra al libro de Job: Edición crítica, traducción y estudio introductorio (Madrid: CSIC, 2004) págs. 295-296.

$89 C f$. Leonard Chappelow, A commentary on the Book of Job in which is inserted the Hebrew text and English translation (Cambridge, 1752) págs. 524-525, y GómEz Aranda, El Comentario de Abraham ibn Ezra, pág. 295. 
gallo en la tradición talmúdica ${ }^{90}$, aunque también hizo referencia a quienes lo entendían como 'corazón', por su raíz שוכה, que significa mira, ve y piensa en los asuntos venideros ${ }^{91}$. No obstante, cabe decir que estos motivos filológicos también se sirven de explicaciones para la interpretación del 'gallo' ${ }^{92}$, sobre todo al tener en cuenta la identificación speculator $=$ gallus generalmente aceptada por lo menos en la edad talmúdica ${ }^{93}$.

El nombre del gallo se repite varias veces en el Talmud ${ }^{94}$, destacando sus virtudes y su valor instructivo para la vida cotidiana humana. Al parecer, las descripciones rabínicas sobre sus características no tienen nada que ver con los versículos a los que atendemos, pero de hecho expresan implícitamente la misma idea fundamental del discurso divino en Job: por un lado, el hombre no cuenta con el motivo de ser arrogante, dado que toda su preeminencia viene de Dios; por otro lado, la sabiduría no se otorga solamente al hombre, sino también a los animales, de los cuales debe aprender con modestia. El sentido doctrinal queda más evidente en la paráfrasis del Targum sobre la alabanza del gallo al Señor ${ }^{95}$. Así que resultaría explicable la incorporación de este animal en la oración matutina judía ${ }^{96}$, lo cual también nos recuerda su figura en la

90 Talmud Bavli, Rosh Hashanah 26a:20. Con referencia a la traducción en inglés de la edición The William Davidson digital edition of the Koren Noé Talmud en línea:

$<$ https://www.sefaria.org/Rosh_Hashanah.26a?lang=en $>$ [última consulta: 29/06/2020].

${ }^{91}$ Comentario de Rashi sobre Job 38,36, cuya traducción en inglés se consulta en línea:

$<$ https://www.chabad.org/library/bible_cdo/aid/16440/showrashi/true\#lt=both $>$ [última consulta: 29/06/2020].

92 Cf. KLeIn, A Comprehensive Etymological Dictionary, pág. 656, s. v. vשִָׁ, y DE ITZsCH, Biblical commentary, págs. 326-327.

93 Cf. Delitzsch, Biblical commentary, págs. 326-327.

${ }^{4}$ Cf. Marcus Jastrow, Dictionary of the Targumim, the Talmud Bavli and Yerush-

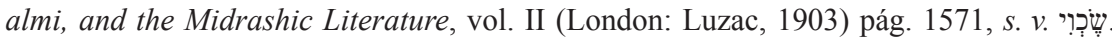

95 Indicado por varios comentaristas. P. ej., «Chaldaeus autem in eo ponit galli intelligentiam, quod laudet Dominum suum» en Diego de ZúÑIGA, 1584, pág. 813.

96 Cf. Dhorme, Le Livre de Job, pág. 540, y Samuel Terrien, «The Book of Job. Exegesis», en The Interpreter's Bible: the Holy Scriptures in the King James and Revised Standard Versions with General Articles and Introduction, Exegesis, Exposition for Each Book of the Bible, vol. III (Nashville: Abingdon Press, 1978) págs. 908-1198: 1178-1179. 
liturgia cristiana ${ }^{97}$. Es posible que Jerónimo tuviera acceso a las fuentes hebreas postbíblicas, que repercutieron en sus traducciones. Fuera cual fuera el motivo primitivo, su interpretación del 'gallo' ha establecido una vinculación coherente entre la primera parte del versículo y el pasaje siguiente, cayendo perfectamente en la tradición cristiana.

No obstante, da la impresión de que la traducción de 'entrañas' en 36a, que se extiende a interpretaciones tales como 'seno', 'interior' o 'espíritu', no construiría ningún paralelismo con el gallo ${ }^{98}$. Pero la verdad es que se ha desarrollado exactamente sobre la base de una tradición tanto pagana como cristiana de la vinculación entre las aves y el alma del hombre. Bajo la influencia del simbolismo pagano, los primeros cristianos asociaban el espíritu con las cosas aladas, que se aceptaba en la tradición patrística ${ }^{99}$. Aunque para los autores cristianos el espíritu se presenta más frecuentemente en la forma de una paloma, en no pocas ocasiones lo describen simplemente como un pájaro ${ }^{100}$. $\mathrm{E}$ incluso, a veces, los renacentistas -especialmente los platónicos florentinos-, con una resonancia platónica, lo consideraban justamente como un gallo, que llegó a convertirse en el símbolo del alma de un filósofo ${ }^{101}$. Es decir, para los autores renacentistas, era conocido el sentido alegórico del gallo como algo equivalente al espíritu. Una de las pruebas puede verse en el poema «Cock-Crowing» de Vaughan, en el que el poeta asocia el gallo con el alma del hombre, dado que la atracción del sol para este animal con «sunnie seed» es efectivamente la misma de Dios - un sol alegórico- para el alma, una semilla sembrada por Él en nuestros cuerpos ${ }^{102}$.

97 Don Cameron Allen, «Vaughan's 'Cock-Crowing' and the Tradition», ELH 21:2 (1954) págs. 94-106: 100.

98 Aparte del sentido gramático, aquí se refiere en particular a un paralelismo semántico; cf. Adele Berlin, The Dynamics of Biblical Parallelism (Bloomington, IN: Indiana University Press, 1985) págs. 88-102.

99 Cf. Allen, «Vaughan's 'Cock-Crowing' and the Tradition», págs. 102-103.

100 Cf. [Ps.] Rabanus Maurus, Allegoriae in universam sacram scripturam, citado de Patrologia Latina (PL), CXII. 871, y Rupertus Tuitiensis, PL, CLXVIII. 294.

$101 C f$. AlLEN, «Vaughan's 'Cock-Crowing' and the Tradition», págs. 103-105.

102 Cf. Henry Vaughan, The Poetical Works of Henry Vaughan: With A Memoir (Boston: James R. Osgood \& Company, 1871) págs. 190-191. 
Además, hay varias interpretaciones alegóricas acerca de las relaciones entre el gallo y el alba en las obras cristianas, como las Moralia de San Gregorio, quien nos explicó minuciosamente la identificación de esta especie de ave con el predicador ${ }^{103}$. Teniendo en cuenta el simbolismo del lucero para el Señor ${ }^{104}$, se percibe una alusión cristológica en la tradición jeronimiana, donde radica la auténtica sabiduría del gallo, que detecta perspicaz y prudentemente ${ }^{105}$ las reglas del movimiento de los astros y siempre alerta a tiempo en voz alta -sus cantos en concordancia de esa 'música' ${ }^{106}$ - a los seres vivos de la llegada del primer rayo de la luz nueva. A pesar de su respeto, Jerónimo criticó que la traducción de los judíos carecía de una desvelación de los sentidos más profundos y misteriosos del texto, mientras que él intentaba ilustrar su valor cristológico ${ }^{107}$, que se manifiesta en las relaciones existentes entre el gallo y la armonía universal, una interpretación que no dejó de producir resonancias en las versiones de sus seguidores como fray Luis -por lo menos en este caso de Job 38,36-37-.

Sin embargo, resultaría difícil aceptar el hecho de que el Creador le dota al ave de una sabiduría superior a la del hombre. En realidad, por una parte, como lo indicado antes, el hombre no es el único que adquiere la gracia divina y debe ser consciente de sus propias limitaciones; por la otra, sería más fácil de entender si tenemos en cuenta la identificación del gallo con Cristo en la tradición cristiana: «Avis est Christus» ${ }^{108}$. Así que la alusión cristológica queda más clara, superando el marco propio del AT. No hay que olvidar el anhelo reiterado por parte de Job de contar con un testigo o mediador que viene de las alturas, cuya esperanza

${ }^{103} C f$. la edición traducida al castellano por Alfonso Álvarez de Toledo: Los morales de sant Gregorio Papa, doctor de la santa yglesia (Sevilla, 1549) lib. XXX, cap. iiij-v.

104 Cf. San Agustín, O. C., págs. 134-135.

105 La alabanza luisiana de la virtud de prudencia del gallo se evidencia en su traducción en terceto de Job; $c f$. Luis DE León, O. C. C., vol. II, pág. 638. 634-635.

106 Cf. Amat, La Sagrada Biblia, pág. 384, y Luis de León, O. C. C., vol. II, págs.

107 Allan K. Jenkins y Patrick Preston, Biblical Scholarship and the Church: A Sixteenth-Century Crisis of Authority (London: Routledge, 2016) págs. 18-19.

108 [Ps.] Maurus, PL, CXII. 871. 
no se cumple hasta la llegada de Cristo ${ }^{109}$. Y en cuanto al anuncio del Salvador, nadie puede enterarse antes que Él mismo.

Así pues, no es nada extraño que en las comparaciones textuales que hemos realizado se puedan encontrar suficientes defensas de la traducción por 'gallo', sobre todo en las versiones y comentarios modernos ${ }^{110}$, con sustentos tanto de la tradición judía como de la cristiana.

\section{2. ¿Entrañas, riñones o ibis?}

La primera parte del versículo 36 también ha sufrido un sinfín de controversias, cuyo enfoque reside en טִּin. Rashi simplemente señaló que eran riñones, mientras que Ramban, aparte de hacer referencia a Jerusalemite Targum, dio una explicación más detallada, indicando la raíz טוח ('estar cubierto') como una posible fuente etimológica, dado que los riñones están cubiertos de grasa ${ }^{111}$. En cambio, Ibn Ezra no estaba de acuerdo y sostenía que se debía traducir por 'entrañas' o extender hacia 'el interior', considerándolo el lugar donde «se conserva la verdad» ${ }^{112}$.

En términos amplios, todas las traducciones de oט̣i por 'entrañas', 'riñones', 'interior' o algo parecido, tanto de judíos como de cristianos, pueden meterse en un mismo grupo. El otro es para la interpretación de 'ibis', otro animal en paralelo al gallo de 36b, lo cual significa un hecho

$109 C f$. Francis I. Andersen, Job: an introduction and commentary (Downers Grove, IL: Inter-Varsity Press, 1976) pág. 19.

110 Hay que notar lo ocurrido en no pocas versiones: aunque no lo traducen así en el cuerpo, en las anotaciones indican que es más justificable entender este versículo como un referente a los animales; $c f$. Michael D. Coogan, (ed.), The New Oxford Annotated Bible with Apocrypha: New Revised Standard Version (New York: Oxford University Press, 2018) pág. 775; TERrIEN, «The Book of Job. Exegesis», págs. 1178-1179, y NIV Study Bible: New International Version (Grand Rapids, MI: Zondervan, 2008) pág. 773, entre otros.

111 Para comentarios de Rambán sobre Job 38,36, véase Mikra'ot Gedolot Ha-Keter, consulta en línea: <https://www.mgketer.org/mikra/1/1/1/mg/0> [última consulta: 29/06/2020], teniendo a la vista la traducción al español en Mariano Gómez ArANDA, El Comentario de Abraham ibn Ezra, pág. 295.

112 Gómez Aranda, El Comentario de Abraham ibn Ezra, pág. 295. 
llamativo para nosotros: ya se viene reconociendo lo razonable de tra-

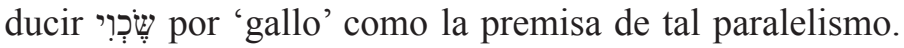

Como lo presentado antes, durante la última centuria, cada vez más versiones se vienen inclinando a interpretar טִin como 'ibis'. Por un lado, piensan en las razones filológicas, creyendo que su origen procede del nombre de un dios egipcio Thoth, que suele ser representado con la cabeza de un ibis -ave venerada por sus predicciones sobre las crecidas del Nilo- para simbolizar la sabiduría ${ }^{113}$; por otro lado, comienzan a consentir el paralelismo semántico entre el gallo y el ibis, puesto que los dos coinciden no solo en ser aves, sino también en su común función anunciadora ante el cambio natural, como profetas del tiempo ${ }^{114}$. Incluso ahora ya no es nada sorprendente encontrar la explicación de ibis en la entrada de טִּז en unos diccionarios de autoridad ${ }^{115}$.

Con esta referencia a animales, se explicaría mejor el papel importante de transición que desempeñan estos versículos, donde se terminan las descripciones sobre el cosmos y entran en el mundo animal, cuyos representantes, el ibis y el gallo, cuentan con instintos que se manifies$\tan$ en sus relaciones con la naturaleza y el universo ${ }^{116}$.

\section{3. ¿Cantidad de las nubes u orden del movimiento cósmico?}

A la vista de la explicación de 37a que hemos realizado, el sustantivo puede referirse tanto a las nubes como al cielo ${ }^{117} \mathrm{y}$ el verbo tiene 'nu-

113 Samuel E. Balentine, Smyth \& Helwys Bible Commentary: Job (Macon, GA: Smyth \& Helwys, 2006) pág. 657.

$114 C f$. Alonso SchöKel, Job, pág. 187; Balentine, Job, pág. 657; Terrien, «The Book of Job. Exegesis», págs. 1178-1179; Bover y CAntera Burgos, Sagrada Biblia, pág. 870; Gordis, The Book of Job, pág. 453, y Dhorme, Le Livre de Job, págs. 540-541, entre otros.

115 Por ejemplo, Ludwig Koenler y Walter Baumgartner, The Hebrew and Aramaic Lexicon of the Old Testament, vol. I (Leiden-New York-Cologne: E. J. Brill, 1994) págs. 373-374.

$116 C f$. Balentine, Job, págs. 657-658.

117 Estudio más detallado al respecto puede verse en Jesús LuZARRAGA, Las tradiciones de la nube en la Biblia y en el judaismo primitivo (Roma: Biblical Institute Press, 1973) págs. 17-21. 
merar' como su sentido original y 'narrar' como un dilatado, de modo que desde la perspectiva filológica resultarían razonables tanto la interpretación de ilustrar la cantidad de las nubes como la más parafrástica de tratar el orden del movimiento de los cielos. En realidad, en la tradición rabínica, nunca se ha llegado a un consenso, sino que varía desde 'dibujar las nubes', 'contar el número de nubes', 'describir las nubes' hasta 'hacer zafiro las nubes', entre otras ${ }^{118}$. Rashi entendía el verbo como יספר ('dirá y cargará con su misión') ${ }^{119}$, enfatizando el poder de control de Dios, en vez de la cantidad numérica.

Habría que tomar en consideración el contexto para encontrar una traducción más adecuada. De hecho, aunque lo parezca, la armonía jeronimiana, o sea, la música luisiana, no ha perdido su resonancia por completo: a pesar de la aparición de 'nubes', se refiere al orden del misterioso movimiento cósmico -en el mismo sentido de 'cielos' en la Vulgata y sus seguidores-, razón por la cual el hombre no es capaz de percibirlo, pero el animal con instinto especial como el gallo lo percata con perspicacia. En todo caso, si lo que este discurso intenta ejemplarizar es la sabiduría de contar el número exacto de las nubes, no la domina en realidad ni el ibis ni el gallo.

Por eso, al tener en cuenta lo razonable de las interpretaciones sobre estos animales, se notarán enseguida las relaciones inexplicables entre el gallo y 37a. Todos los biblistas que defienden al 'ibis' lo vinculan con su prenuncio de la crecida del Nilo, aludiendo al fenómeno de la lluvia en $37 \mathrm{~b}$, de modo que el gallo de $36 \mathrm{~b}$ quedaría muy probablemente relacionado con $37 \mathrm{a}$, con lo cual se constituye un chiasmus ${ }^{120}$. No obstante, ya sea en la tradición profana o la sagrada, la cristiana o la judía, es bien sabido que la sabiduría más distinguible del gallo no está vinculada con la lluvia, sino con su conocimiento del tiempo y su canto puntual, que no tiene nada que ver con la cantidad de las nubes, sino con la rotación de la Tierra -o la revolución de los astros en los tiempos geocéntricos-, dentro del marco del orden universal establecido por el Creador. De esta

118 Gómez Aranda, El Comentario de Abraham ibn Ezra, págs. 296-297.

119 Comentario de Rashi sobre Job 38,37. Consulta en línea: <https://www.sefaria. org/Rashi_on_Job.38.37.1?lang=en\&with=Tanakh\&lang2=en $>,<$ https://www.chabad. org/library/bible_cdo/aid/16440/showrashi/true\#lt=both $>$ [última consulta: 26/06/2020].

120 Cf. Andersen, Job, págs. 37-40. 
manera, el instinto del animal se aclara y se relaciona estrechamente con el universo y la naturaleza, por lo cual los versículos antecedentes pueden desarrollarse naturalmente hacia el reino animal con coherencia.

Además, el discurso sobre los fenómenos naturales y el sobre los animales llegan a un mismo destino: mostrar el poder imponderable de control de Dios. Toda la Creación tiene su regla y todos los cambios dependen de su control. Es decir, el universo se encuentra en un estado armonioso de orden, incluida la sabiduría del animal, que supera el límite del hombre ${ }^{121}$. Así que llegamos al sentido moral de la armonía cósmica, que se transmite tácitamente por medio de estos dos versículos. Sin duda alguna, Job es un hombre de virtud, pero no conocía perfectamente la limitación humana ni las relaciones correctas entre el hombre y Dios. Este problema no lo resuelve Él dando respuestas directamente, sino con la muestra de una serie de cosas que pueden despertarle de su error, entre las cuales se destaca la «música de cielos» como un buen testimonio. Se trata de una 'música' inaudible para el hombre, pero accesible para el animal por su particular prudencia y sabiduría otorgada por Dios, lo cual supone una lección profunda para Job.

En realidad, a lo largo de la historia no pocos autores han intentado dar una explicación acerca de por qué no somos capaces de oír los sonidos engendrados por el movimiento de las esferas, bien por la plenitud del ruido, bien por la lejanía, bien por la cotidianidad, etc. ${ }^{122}$ Sin embargo, según la tradición bíblica y la cristiana, esta armonía se convierte en algo 'callado' como consecuencia de la caída del hombre ${ }^{123}$, demostrando el significado moral de esta concepción cosmológica cristianizada. Por lo tanto, el hombre debe reconocer su injusticia, por lo menos por su pecado original, por lo cual le resulta inaccesible a la música

121 Cf. BAlentine, Job, pág. 649; A. van Selms, Job: a practical commentary (Grand Rapids, MI: W.B. Eerdmans Pub. Co., 1985) págs. 144-145, y Raymond Edward Brown, The New Jerome Biblical Commentary (Englewood Cliffs, NJ: Prentice-Hall, 1990) págs. 486-487.

122 Cf. Cícerón, Sobre la República, pág. 166; León Hebreo, Diálogos de amor (Madrid: Tecnos, 2002), y Hicks, Composing the world, págs. 190-192, entre otros.

123 Véanse John Hollander, The untuning of the sky (Princeton, NJ: Princeton University Press, 1961) págs. 316-317, y Jialuan Hu, El cielo estrellado histórico: la cosmología tradicional occidental y la poesía renacentista inglesa [en chino] (Beijing: Peking University Press, 2001) págs. 123-124. 
cósmica, especialmente en comparación con la perspicacia del gallo, que supondría la prudencia ante la llegada de la salvación.

El Libro de Job revela una verdad importante: el sufrimiento es una carga pesada para todos ${ }^{124}$, que coincide justamente con lo que dice fray Luis en el comienzo de la Dedicatoria de su Exposición ${ }^{125}$. El dolor de Job viene en gran medida de su falta de consciencia del pecado ${ }^{126}$. Según San Agustín, para quien los números y proporciones musicales son manifestaciones del plan de Dios creador y rector del universo $^{127}$, la confesión, que consiste en uno de los temas fundamentales en Job, no aparece espontáneamente del corazón del hombre, sino con el auxilio sagrado, como fruto de la obra de Dios ${ }^{128}$. En este sentido, el ejemplo magnífico de la armonía de las esferas no es otra cosa que un impulsador.

Por otra parte, las preguntas de Job atañen implícitamente a la teodicea. El Creador aprovecha todas sus creaciones para servirle de respuesta: el sufrimiento de Job también ocurre bajo su dominio, como todo el universo, y el hombre no debe considerarse justo ni poner la justicia divina en duda, sino humillarse y ser temeroso ${ }^{129}$. De esta manera, Dios manifiesta al hombre el fin del aprendizaje de los animales y de todo el universo, que reside en descubrirle a Él leyendo el Libro de la Naturaleza, incluida la música de las esferas. Job no lo entendió hasta el final. Siendo testigo de la gloria divina, aprendió con asombro y se dio cuenta de su pecado en el mismo instante de su reconciliación ${ }^{130}$, por lo cual por fin dijo: «Auditu auris audivi te, nunc autem oculus meus videt te» ${ }^{131}$. Todo esto nos recuerda la Oda VIII «Noche serena» de fray Luis,

\footnotetext{
${ }^{124} C f$. Andersen, Job, págs. 64-74.

125 «Todos padecen trabajos, porque el padecer es debido a la culpa, y todos nacen en ella»; apud Luis de León, O. C. C., vol. II, pág. 27.

126 Cf. Andersen, Job, págs. 268-269.

127 Cf. la Introducción de Moreno y López Eisman en Agustín, Sobre la música, págs. 28-29.

$128 C f$. la Introducción de de Luis en Agustín, O. C., pág. 8.

129 Cf. Andersen, Job, págs. 64-74.

130 Cf. Samuel Terrien, «The Book of Job. Introduction», en The Interpreter's Bible, vol. III (Nashville: Abingdon Press, 1978) págs. 877-905: 902.

131 Job 42,5; citado de la Vulgata, 1514, fol. $77 \mathrm{v}$.
} 
quien siempre alberga el anhelo de acercarse a Dios a través de la armonía.

\section{Conclusiones}

A través de la comparación textual y la revisión de los estudios hermenéuticos, se ha observado que, aunque tiene variantes y todavía carece

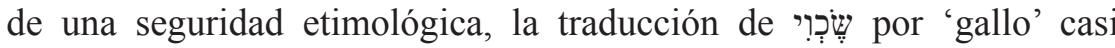
siempre ocupa un lugar predominante desde las primeras versiones hasta las más recientes. Además, se vuelve cada día mayor el número de los biblistas que se inclinan a considerar poralelamente como 'ibis'. Sin embargo, parece que falta una explicación convincente sobre su vinculación semántica con el versículo siguiente, por lo cual nos resultaría necesario reflexionar de nuevo sobre la interpretación convencional y no es una mala idea acudir al origen jeronimiano.

En cuanto a nuestro punto de partida, la exposición parafrástica sobre la «música de cielos» de fray Luis de León, en el caso de Job 38,36-37, es probable que el exégeta no siga la Vulgata totalmente por obligación ${ }^{132}$, sino que también la aproveche para dar una coherencia al contexto, partiendo de una tradicional concepción cosmológica cristianizada, así como expresar su anhelo personal de la armonía, un lazo perfecto entre el hombre, el universo y Dios. De esta manera, aparte de demostrar la razón de la traducción jeronimiana y la peculiaridad literaria de su exégesis - no olvidemos su dimensión de dualidad: erudito bíblico y poeta distinguido a la vez-, el humanista cristiano consigue practicar la ciencia filológica como auxiliar para la teología.

Pero no intento confirmar lo correcto de la paráfrasis luisiana sobre Job, ni en un sentido filológico ni en un sentido exegético. La lectura de Job nunca ha sido fácil y su estudio hermenéutico supone un trabajo interminable. Frente a tal controversia que ha durado casi dos mil años ${ }^{133}$, por el momento sería demasiado aventurado sacar conclusiones

132 Para algunos estudiosos, es una pena que los excelentes conocedores del hebreo como fray Luis y Pineda se viesen obligados a defender la Vulgata a cualquier precio; $c f$. Alonso SchöKel y Sicre Díaz, Job, pág. 106.

133 Cf. Andersen, Job, pág. 279. 
definitivas de cualquier tipo, cuya resolución necesita más descubrimientos y avances de muchos otros estudios interdisciplinares, tales como los arqueológicos, históricos, paleográficos, etc. Por eso, sería mejor aceptar y respetar esta incertidumbre, e incluso aprovechar este espacio abierto a discusiones, donde por lo menos la 'música' luisiana nos ha ofrecido una posibilidad favorable de lectura.

Recibido: $12 / 11 / 2020$

Aceptado: 02/03/2021 